NBER WORKING PAPER SERIES

\title{
A FISCAL THEORY OF SOVEREIGN RISK
}

\author{
Martín Uribe \\ Working Paper 9221 \\ http://www.nber.org/papers/w9221 \\ NATIONAL BUREAU OF ECONOMIC RESEARCH \\ 1050 Massachusetts Avenue \\ Cambridge, MA 02138 \\ September 2002
}

I would like to thank Stephanie Schmitt-Grohé and seminar participants at the European Central Bank and the 2002 meeting of the Society for Economic Dynamics held in New York, NY. for helpful comments. The views expressed herein are those of the author and not necessarily those of the National Bureau of Economic Research.

(C) 2002 by Martín Uribe. All rights reserved. Short sections of text, not to exceed two paragraphs, may be quoted without explicit permission provided that full credit, including (C) notice, is given to the source. 
A Fiscal Theory of Sovereign Risk

Martín Uribe

NBER Working Paper No. 9221

September 2002

JEL No. E6, F41

\begin{abstract}
This paper presents a fiscal theory of sovereign risk and default. Under certain monetaryfiscal regimes, the risk of default, and thus the emergence of sovereign risk premia, are inevitable. The paper characterizes the equilibrium processes of the sovereign risk premium and the default rate under a number of alternative monetary policy arrangements. Under some of the policy environments considered, the expected default rate and the sovereign risk premium are zero although the government defaults regularly. Under other monetary regimes the default rate and the sovereign risk premium are serially correlated and therefore forecastable. Environments are characterized under which delaying default is counterproductive.
\end{abstract}

\author{
Martín Uribe \\ Department of Economics \\ University of Pennsylvania \\ 3718 Locust Walk \\ Philadelphia, PA 19104 \\ and NBER \\ uribe@econ.upenn.edu
}




\section{Introduction}

Certain monetary-fiscal arrangements are incompatible with price stability and government solvency. Consider, for example, the case of an independent central bank whose policy is to peg the price level. Under this monetary regime, the government cannot use the price level as a shock absorber of negative fiscal shocks. Specifically, by sticking to a price level target, the government gives up its ability to inflate away part of the real value of public debt via surprise inflation in response to a sudden deterioration of the fiscal budget. Under these circumstances, default of the public debt is inevitable. ${ }^{1}$

Policy regimes of this type, under which debt repudiation is, under certain states of the world the only possible outcome, are not unheard of. A point in case is the recent debt crisis in Argentina. Between 1991 and early 2002, Argentina pegged the domestic price of tradables to the US counterpart by fixing the peso/dollar exchange rate. Abandoning the exchange-rate peg was never an easy option for the Argentine government. This is because the peg was instituted by a law of Congress - the 1991 Convertibility Law — which required the enactment of another law to deactivate it. In the midst of a prolonged recession, in 2001 doubts began to be cast about the government's ability to curb fiscal imbalances. These fears placed the country risk premium, measured by the difference between the interest rate on Argentine and US dollar-denominated government bonds of similar maturities, over 1,800 basis points, among the world's highest at the time. Eventually, the Argentine government defaulted; first on interest obligations, in December of 2001, and shortly thereafter on the entire principal.

Price level targeting is not the only monetary arrangement under which pressures for default can arise under certain fiscal scenarios. Consider, for example, the case of a central bank that aggressively pursues an inflation target by setting the nominal interest rate as an increasing function of inflation with a reaction coefficient larger than unity. This type of policy rule is often referred to as a Taylor rule after John Taylor's (1993) seminal paper. Suppose that, at the same time, the fiscal authority follows an active stance whereby it does not adjust the primary deficit to ensure intertemporal solvency. Under this policy mix, if the government refrains from defaulting, then price stability is in general unattainable. In particular, the equilibrium rate of inflation converges to either plus or minus infinity. Loyo (1999) refers to the latter equilibrium as a 'fiscalist hyperinflation.' Given this monetaryfiscal regime, default is a necessary consequence if price stability is to be preserved. An example of the policy regime described here is given by Brazil. After abandoning a crawling

\footnotetext{
${ }^{1}$ Krugman's (1979) celebrated model of balance of payments crises is an example in which the aforementioned incompatibility is resolved by abandoning the price stability goal.
} 
peg policy, since mid 1999 the Brazilian central bank has actively used the interest rate as an instrument to target inflation. Although in recent years fiscal discipline has been enhanced, the Brazilian Treasury is facing serious difficulties implementing additional fiscal reforms necessary to slowdown the rapid growth in public debt. Interestingly, a growing number of observers are beginning to consider a 'unilateral restructuring' of Brazil's public debt as a likely way out of hyperinflation. ${ }^{2}$

The focus of this paper is to characterize the equilibrium behavior of default and the country risk premium in policy environments under which the government cannot guarantee the full service of public obligations without relinquishing price stability. A central question this paper seeks to answer is how different monetary policy specifications affect the equilibrium behavior of default and sovereign risk premia. The analysis is organized around two canonical policy arrangements. Under both environments fiscal policy is assumed to be 'active' in the sense of Leeper (1991). Specifically, real primary surpluses are assumed to be exogenous and random. In one of the policy regimes considered, the central bank pegs the price level. In the other, the monetary authority follows a Taylor rule.

Our characterization of equilibrium under default reveals that the properties of the equilibrium stochastic process followed by the default rate and the sovereign risk premium depend heavily upon the underlying monetary policy regime. For example, in the Taylor-rule economy, the expected default rate and the country risk premium are zero. This means that the default rate is unforecastable. By contrast, in the price-targeting economy current and past fiscal deficits predict future default rates. Moreover, in the price-targeting economy the fiscal authority has more degrees of freedom in setting the default rate than in the Taylor-rule economy.

Clearly, having to default is a situation no policymaker wishes to be involved in. So procrastination is commonplace. Sometimes governments choose to let go of their price stability goals in the hopes of retaking them after inflating their way out of default. A natural question, therefore, is what standard general equilibrium models tell us about the consequences of delaying default. We find that substituting a temporary increase in inflation for default is not always possible. Specifically, we identify situations in which postponing the decision to default leads to a hyperinflationary situation that in order to be stopped requires an eventual default of larger dimension than the one that would have taken place had the government not chosen to procrastinate.

\footnotetext{
${ }^{2}$ See, for example, the articles by Ted Truman (senior fellow at the Institute for International Economics, former assistant secretary of the Treasury for international affairs, and former director of the Division of International Finance at the Federal Reserve Board) published in the Financial Times on June 25, 2002, and by Joaquín Cottani (chief economist of Lehman Brothers) published in the Argentine newspaper La Nación on June 23, 2002. See also the June 29, 2002 issue of The Economist.
} 
We close this introduction by pointing out two assumptions that will be maintained throughout the paper. First, the analysis departs from a large existing literature on sovereign debt in that here, given the monetary and fiscal regimes, the government is assumed to always choose to honor its financial obligations if it can. ${ }^{3}$ Second, we assume that public debt is nonindexed. In practice this is not the case. Typically, emerging market debt is denominated in foreign currency or stipulates returns tied to some domestic price index. Introducing indexation does not affect the qualitative results of the paper. But it does introduce quantitative differences. This is because the more pervasive indexation is, the larger are the price level changes necessary to obtain a given decline in government's total liabilities. $^{4}$

The remainder of the paper is organized in six sections. Section 2 presents the model. Section 3 derives a basic equilibrium relation linking the default rate, future expected fiscal surpluses, and initial government liabilities. Section 4 characterizes the equilibrium behavior of default and sovereign risk when monetary policy takes the form of a Taylor rule. Section 5 analyzes the consequences of delaying default. Section 6 studies default and country risk under a price-level peg. Section 7 closes the paper.

\section{The Model}

Consider an economy populated by a large number of identical households, each of which has preferences described by the utility function

$$
E_{0} \sum_{t=0}^{\infty} \beta^{t} U\left(c_{t}\right)
$$

where $c_{t}$ denotes consumption of a perishable good, $\beta \in(0,1)$ denotes the subjective discount factor, and $E_{0}$ denotes the mathematical expectation operator conditional on information available in period 0 . The single-period utility function $U$ is assumed to be increasing, strictly concave, and twice continuously differentiable.

In each period $t \geq 0$, households can purchase nominal state-contingent claims that pay one unit of currency in a specified state of period $t+1$. We let $D_{t+1}$ denote the random variable indicating the number of state-contingent claims purchased in period $t$ paying off in each particular state of period $t+1$. In addition, each period households are endowed with

\footnotetext{
${ }^{3}$ For a survey of the literature on sovereign debt in settings where governments that are not forced to default by fiscal constraints nevertheless always choose to do so if they find it optimal, see Eaton and Fernández (1995).

${ }^{4}$ Even if the totality of public debt was indexed, changes in the price level would still introduce fiscal effects in the presence of fiat money. In this paper we do away with money for analytical simplicity.
} 
an exogenous and constant amount of perishable goods $y$ and pay real lump-sum taxes in the amount $\tau_{t}$. The flow budget constraint of the household in period $t$ is then given by:

$$
P_{t} c_{t}+E_{t} r_{t+1} D_{t+1}+P_{t} \tau_{t} \leq D_{t}+P_{t} y
$$

where $P_{t}$ denotes the price level, and $r_{t+1}$ denotes the period- $t$ price of a claim to one unit of currency in a particular state of period $t+1$ divided by the probability of occurrence of that state conditional on information available in period $t$. The left-hand side of the budget constraint represents the uses of wealth: consumption spending, purchases of contingent claims, and tax payments. The right-hand side displays the sources of wealth: the payoff of contingent claims acquired in the previous period and the endowment. In addition, the household is subject to the following borrowing constraint that prevents it from engaging in Ponzi schemes:

$$
\lim _{j \rightarrow \infty} E_{t} q_{t+j} D_{t+j} \geq 0
$$

at all dates and under all contingencies. The variable $q_{t}$ represents the period-zero price of one unit of currency to be delivered in a particular state of period $t$ divided by the probability of occurrence of that state given information available at time 0 and is given by

$$
q_{t}=r_{1} r_{2} \ldots r_{t}
$$

with $q_{0} \equiv 1$.

The household chooses the set of processes $\left\{c_{t}, D_{t+1}\right\}_{t=0}^{\infty}$, so as to maximize (1) subject to (2) and (3), taking as given the set of processes $\left\{P_{t}, r_{t+1}, \tau_{t}\right\}_{t=0}^{\infty}$ and the initial condition $D_{0}$. Let the multiplier on the flow budget constraint be $\lambda_{t} / P_{t}$. Then the first-order conditions associated with the household's maximization problem are (2) and (3) holding with equality, and

$$
\begin{gathered}
U_{c}\left(c_{t}\right)=\lambda_{t} \\
\frac{\lambda_{t}}{P_{t}} r_{t+1}=\beta \frac{\lambda_{t+1}}{P_{t+1}} .
\end{gathered}
$$

The interpretation of these optimality conditions is straightforward. Condition (4) states that the marginal utility of consumption must equal the marginal utility of wealth, $\lambda_{t}$, at all times. Equation (5) represents a standard pricing equation for one-step-ahead nominal 
contingent claims. Note that $E_{t} r_{t+1}$ is the period- $t$ price of an asset that pays one unit of currency in every state of period $t+1$. Thus $E_{t} r_{t+1}$ represents the inverse of the risk-free gross nominal interest rate. Formally, letting $R_{t}^{f}$ denote the gross risk-free nominal interest rate, we have

$$
R_{t}^{f}=\frac{1}{E_{t} r_{t+1}}
$$

\subsection{The Fiscal Authority}

The government levies lump-sum taxes, $\tau_{t}$, which are assumed to follow an exogenous, stationary, stochastic process. For simplicity, we assume that $\tau_{t}$ follows an $\operatorname{AR}(1)$ process:

$$
\tau_{t}-\bar{\tau}=\rho\left(\tau_{t-1}-\bar{\tau}\right)+\epsilon_{t}
$$

where $\bar{\tau}$ is the unconditional mathematical expectation of taxes, the parameter $\rho \in[0,1)$ denotes the serial correlation of taxes, and $\epsilon_{t} \sim N\left(0, \sigma_{\epsilon}^{2}\right)$ is an iid random tax innovation. In period $t$, the government nominal bonds, denoted by $B_{t}$, that pay a gross nominal interest rate $R_{t}$ in period $t+1$. The interest rate $R_{t}$ is known in period $t$. Government bonds are risky assets. For each period the fiscal authority may default on a fraction $\delta_{t}$ of its total liabilities. A focal point of our analysis is the characterization of the equilibrium distribution of the default rate $\delta_{t}$. The government's sequential budget constraint is then given by

$$
B_{t}=R_{t-1} B_{t-1}\left(1-\delta_{t}\right)-\tau_{t} P_{t} ; \quad t \geq 0
$$

\subsection{Equilibrium}

In equilibrium the goods market must clear. That is,

$$
c_{t}=y \text {. }
$$

The fact that in equilibrium consumption is constant over time implies, by equation (4), that the marginal utility of wealth $\lambda_{t}$ is also constant. In turn, the constancy of $\lambda_{t}$ implies, by equation (5), that $r_{t+1}$ collapses to

$$
r_{t+1}=\beta \frac{P_{t}}{P_{t+1}}
$$


This expression and equation (6) then imply that in equilibrium the nominally risk free interest rate $R_{t}^{f}$ is given by

$$
R_{t}^{f}=\beta^{-1}\left[E_{t} \frac{P_{t}}{P_{t+1}}\right]^{-1}
$$

Because all households are assumed to be identical, in equilibrium there is no borrowing or lending among them. Thus, all interest-bearing asset holdings by private agents are in the form of government securities. That is,

$$
D_{t}=R_{t-1} B_{t-1}\left(1-\delta_{t}\right)
$$

at all dates.

Optimizing households must be indifferent between holding government bonds and state contingent bonds. This means that the following Euler equation must hold:

$$
\lambda_{t}=\beta R_{t} E_{t}\left(1-\delta_{t+1}\right) \frac{P_{t}}{P_{t+1}} \lambda_{t+1}
$$

We are now ready to define an equilibrium.

Definition 1 A rational expectations competitive equilibrium is a set of processes $\left\{P_{t}, B_{t}\right.$, $\left.R_{t}, R_{t}^{f}, \delta_{t}\right\}_{t=0}^{\infty}$ satisfying

$$
\begin{gathered}
1=\beta R_{t}^{f} E_{t} \frac{P_{t}}{P_{t+1}} ; \quad R_{t}^{f} \geq 1 \\
1=\beta R_{t} E_{t}\left(1-\delta_{t+1}\right) \frac{P_{t}}{P_{t+1}} \\
B_{t}=R_{t-1} B_{t-1}\left(1-\delta_{t}\right)-P_{t} \tau_{t} \\
\lim _{j \rightarrow \infty} \beta^{t+j+1} E_{t} R_{t+j}\left(1-\delta_{t+j+1}\right) \frac{B_{t+j}}{P_{t+j+1}}=0,
\end{gathered}
$$

along with a definition of monetary policy and further restrictions on fiscal policy, given $R_{-1} B_{-1}$ and the exogenous process for lump-sum taxes $\left\{\tau_{t}\right\}_{t=0}^{\infty}$. 


\section{The Equilibrium Default Rate}

We now derive a key implication of the model for the relation between the equilibrium default rate, expected future fiscal deficits, and initial public debt. Multiplying the left- and righthand sides of equilibrium condition $(11)$ by $R_{t}\left(1-\delta_{t+1}\right)$ and iterating forward $j$ times one can write

$$
\begin{aligned}
R_{t+j} B_{t+j}\left(1-\delta_{t+j+1}\right)= & \left(\prod_{h=0}^{j} R_{t+h}\left(1-\delta_{t+h+1}\right)\right) R_{t-1} B_{t-1}\left(1-\delta_{t}\right) \\
& -\sum_{h=0}^{j}\left(\prod_{k=h}^{j} R_{t+k}\left(1-\delta_{t+k+1}\right)\right) P_{t+h} \tau_{t+h}
\end{aligned}
$$

Divide both sides by $P_{t+j}$ to get

$$
\begin{aligned}
R_{t+j} \frac{B_{t+j}}{P_{t+j+1}}\left(1-\delta_{t+j+1}\right)= & \left(\prod_{h=0}^{j} R_{t+h}\left(1-\delta_{t+h+1}\right) \frac{P_{t+j}}{P_{t+j+1}}\right) R_{t-1} \frac{B_{t-1}}{P_{t}}\left(1-\delta_{t}\right) \\
& -\sum_{h=0}^{j}\left(\prod_{k=h}^{j} R_{t+k}\left(1-\delta_{t+k+1}\right) \frac{P_{t+k}}{P_{t+k+1}}\right) \tau_{t+h}
\end{aligned}
$$

Apply the conditional expectations operator $E_{t}$ on both sides of this expression, use the equilibrium condition (10), and apply the law of iterated expectations to get

$$
E_{t} R_{t+j} \frac{B_{t+j}}{P_{t+j+1}}\left(1-\delta_{t+j+1}\right)=\beta^{-j-1} R_{t-1} \frac{B_{t-1}}{P_{t}}\left(1-\delta_{t}\right)-\sum_{h=0}^{j} \beta^{h-j-1} E_{t} \tau_{t+h}
$$

Now multiply both sides of this equation by $\beta^{j}$, take the limit for $j \rightarrow \infty$, and use equilibrium condition (12) to obtain

$$
0=R_{t-1} \frac{B_{t-1}}{P_{t}}\left(1-\delta_{t}\right)-\sum_{h=0}^{\infty} \beta^{h} E_{t} \tau_{t+h}
$$

If one sets the default rate to zero, this expression collapses to the central equation of the fiscal theory of price level determination (Cochrane, 1998; Sims, 1994; Woodford, 1994). In that literature, the above expression determines the equilibrium price level. In general, the above equation contains two non-predetermined endogenous variables, $\delta_{t}$ and $P_{t}$. Solving for 
the equilibrium default rate $\delta_{t}$ we finally obtain

$$
\delta_{t}=1-\frac{\sum_{h=0}^{\infty} \beta^{h} E_{t} \tau_{t+h}}{R_{t-1} B_{t-1} / P_{t}} ; \quad t \geq 0
$$

This expression, describing the law of motion of the equilibrium default rate, is quite intuitive. It states that the default rate is zero - that is, the government honors its outstanding obligations in the full extent-when the present discounted value of primary surpluses is expected to be equal to the real value of total initial government liabilities. In this case, the government does not need to repudiate its commitments because it is able to raise enough surpluses in the future to pay the interest on its existing real obligations. The government defaults on its debt whenever the present discounted value of primary fiscal surpluses falls short of total real initial liabilities. The extent of the default-i.e., how close $\delta_{t}$ is to one - depends on the gap between real government liabilities and the present value of future expected tax receipts. Note that in computing the present discounted value of fiscal surpluses the real risk-free interest rate is applied, which in equilibrium coincides with the inverse of the subjective rate of discount, $1 / \beta$. Using the $\operatorname{AR}(1)$ process assumed for $\tau_{t}$ (equation $(7)$ ), the above expression becomes

$$
\delta_{t}=1-\frac{(1-\beta)\left(\tau_{t}-\bar{\tau}\right)+(1-\beta \rho) \bar{\tau}}{R_{t-1} B_{t-1} / P_{t}(1-\beta)(1-\beta \rho)} ; \quad t \geq 0
$$

Intuitively, this expression shows that given the level of initial real government liabilities, $R_{t-1} B_{t-1} / P_{t}$, the more persistent is the tax process - i.e., the larger is $\rho$ - the larger is the default on public debt triggered by a given decline in current tax revenues.

\section{Taylor Rules and Default}

In the past two decades, monetary policy in industrialized countries has taken the form of an interest-rate feedback rule whereby the short term nominal interest rate is set as a function of inflation and the output gap (Taylor, 1993; and Clarida et al., 1998). Moreover, estimates of this feedback rule feature a slope with respect to inflation that is significantly above unity, typically around 1.5. More recently, a number of developing countries, notably Brazil, have adopted similar active interest-rate rules with the objective of targeting inflation. To capture this empirical observation, we consider a monetary regime characterized by a linear rule of 
the form: $:^{5}$

$$
R_{t}=R^{*}+\alpha\left(\frac{P_{t}}{P_{t-1}}-\pi^{*}\right)
$$

We assume that monetary policy is active, that is, that $\alpha \beta>1$.

\subsection{Impossibility of Achieving the Inflation Target Without De- faulting}

Can the government ensure an inflation path equal to the target $\pi^{*}$ without ever resorting to default? The answer to this question is no. To see why, suppose that the government sets

$$
\delta_{t}=0 ; \quad t \geq 0
$$

The complete set of equilibrium conditions is then given by (15), (16), and the equations contained in definition 1. Equations (13) and (16) imply that $P_{0}$ is given by

$$
P_{0}=\frac{R_{-1} B_{-1}}{\sum_{h=0}^{\infty} \beta^{h} E_{0} \tau_{h}} .
$$

The numerator on the right-hand side of this expression is predetermined in period 0 . The denominator, on the other hand, is determined in period 0 , but is exogenously given. This means that in general $P_{0}$ will be different from $P_{-1} \pi^{*}$, or, equivalently, that the equilibrium inflation rate in period zero will in general be off target. Furthermore, the monetary authority will miss the inflation target not only in period zero but at every subsequent date. In particular, the equilibrium features either hyperinflation or hyperdeflation. To see why, assume for simplicity that taxes are non-stochastic and consider perfect-foresight equilibria. Let $\pi_{t} \equiv P_{t} / P_{t-1}$ denote the gross inflation rate in period $t$. Then combining equations (10) and (15) we obtain the following difference equation in $\pi_{t}$ :

$$
\pi_{t+1}=\alpha \beta \pi_{t}+(1-\alpha \beta) \pi^{*}
$$

In deriving this expression we set $R^{*}=\pi^{*} / \beta$, to ensure that the inflation target $\pi^{*}$ is a steady-state solution to the above difference equation. It follows by the fact that $\alpha \beta>1$, that if $\pi_{0}>\pi^{*}$ then $\pi_{t} \rightarrow \infty$. In this case, the economy embarks in a hyperinflation. Loyo (1999) refers to this equilibrium as a 'fiscalist hyperinflation,' and argues that the

\footnotetext{
${ }^{5}$ Note that we do not include a term depending on the output gap because in the endowment economy considered here the output gap is nil at all times.
} 
monetary/fiscal regime that gives rise to these dynamics was in place in Brazil during the high inflation episode of the early 1980s.

On the other hand, if $\pi_{0}<\pi^{*}$, then $\pi_{t} \rightarrow-\infty$, and the economy falls into a hyperdeflation. Of course, the inflation rate cannot converge to minus infinity because in that case, according to the linear monetary policy rule (15), the nominal interest rate would reach a negative value in finite time, which is impossible. It follows from the work of Schmitt-Grohé and Uribe (2000) and Benhabib, Schmitt-Grohé, and Uribe (2001,2002) that the zero bound on the nominal interest rate implies that when $\pi_{0}<\pi^{*}$, the economy converges to a 'liquidity trap,' characterized by low and possibly negative inflation and low and possibly zero nominal interest rates.

\subsection{Unforecastability of the Default Rate}

It follows from the preceeding analysis that if the government is to preserve price stability (i.e., if it is to succeed in attaining the inflation target $\pi^{*}$ ), then it must default sometimes. It turns out that if $\delta_{t}$ is allowed to be different from zero, then the government can indeed ensure a constant rate of inflation equal to $\pi^{*}$. That is, the monetary authority can set

$$
\frac{P_{t}}{P_{t-1}}=\pi^{*} ; \quad t \geq 0 .
$$

This expression along with the Taylor rule (15) and the equations listed in definition 1 represent the complete set of equilibrium conditions. Equations (15) and (17) imply that $R_{t}=R^{*}=\pi^{*} / \beta$ for all $t \geq 0$. (We are again assuming that $R^{*}=\pi^{*} / \beta$.) The Euler equation (9) then implies that

$$
E_{t} \delta_{t+1}=0 ; \quad t \geq 0
$$

This means that the equilibrium default rate in effect in period $t+1$ is unforecastable in

period $t$. The exact equilibrium process followed by $\delta_{t}$ can be obtained with the help of equation (13). Evaluating that expression at $t=0$, yields

$$
\delta_{0}=1-\frac{\pi^{*} \sum_{h=0}^{\infty} \beta^{h} E_{0} \tau_{h}}{R_{-1} B_{-1} / P_{-1}} .
$$

The numerator on the right-hand side of this expression is exogenously given. At the same time, the denominator is predetermined in period 0 . So the above equation fully characterizes the equilibrium default rate in period 0 . The default rate is increasing in the initial level of real government liabilities and decreasing in the expected present discounted value of future 
primary surpluses.

In periods $t>0$, equation (13) and the fact that $R_{t-1}=\pi^{*} / \beta$ imply that the default rate is given by

$$
\delta_{t}=1-\frac{\beta \sum_{h=0}^{\infty} \beta^{h} E_{t} \tau_{t+h}}{B_{t-1} / P_{t-1}} ; \quad t \geq 1
$$

In this expression, $B_{t-1} / P_{t-1}$ is an endogenous variable, which we want to express in terms of exogenous variables. To this end, note that equation (11) implies that

$$
\frac{B_{t-1}}{P_{t-1}}=\frac{R_{t-2} B_{t-2}}{P_{t-1}}\left(1-\delta_{t-1}\right)-\tau_{t-1} ; \quad t \geq 1
$$

Using equations $(18)$ and $(19)$ to eliminate $\frac{R_{t-2} B_{t-2}}{P_{t-1}}\left(1-\delta_{t-1}\right)$ from this expression yields

$$
\frac{B_{t-1}}{P_{t-1}}=\sum_{h=0}^{\infty} \beta^{h} E_{t-1} \tau_{t-1+h}-\tau_{t-1} ; \quad t \geq 1,
$$

or

$$
\frac{B_{t-1}}{P_{t-1}}=\beta \sum_{h=0}^{\infty} \beta^{h} E_{t-1} \tau_{t+h} ; \quad t \geq 1 .
$$

Finally, using this expression to eliminate $B_{t-1} / P_{t-1}$ from (19) we obtain the following expression for the equilibrium default rate:

$$
\delta_{t}=1-\frac{\sum_{h=0}^{\infty} \beta^{h} E_{t} \tau_{t+h}}{\sum_{h=0}^{\infty} \beta^{h} E_{t-1} \tau_{t+h}} ; \quad t \geq 1
$$

This equation states that in any period $t>0$, the government defaults when the present discounted value of primary fiscal surpluses is below the value expected for this variable in period $t-1$. That is, the government defaults in response to unanticipated deteriorations in expected future tax receipts. Note that the fact that $\delta_{t}$ has mean zero implies that sometimes - when $\delta_{t}<0$ - the government subsidizes bond holders. ${ }^{6}$ One might think that

\footnotetext{
${ }^{6}$ The result that the default rate has mean zero depends in part on our maintained assumption that $R^{*}=\pi^{*} / \beta$. If one assumes that $R^{*}>\pi^{*} / \beta$, then an equilibrium in which the inflation rate is always equal to the target $\left(\pi_{t}=\pi^{*}\right)$ still exists. In this case, the Taylor rule (15) implies that the equilibrium interest rate is constant and equal to $R^{*}$. In turn, the Euler equation (10) implies that the conditional expectation of the default rate in period $t+1>0$ given information available in $t$ is given by $E_{t} \delta_{t+1}=1-\beta R^{*} / \pi^{*}>0$. It is easy to show that the equilibrium default rate in period 0 is still given by equation (18), while the default rate in periods $t>0$ is given by $\delta_{t}=1-\frac{\pi^{*}}{\beta R^{*}} \frac{\sum_{h=0}^{\infty} \beta^{h} E_{t} \tau_{t+h}}{\sum_{h=0}^{\infty} \beta^{h} E_{t-1} \tau_{t+h}} ; \quad t \geq 1$. Note that, ceteris paribus, the default rate is decreasing in the inflation target $\pi^{*}$ and increasing in the interest rate target $R^{*}$. The intuition behind this result is straightforward. The ratio $R^{*} / \pi^{*}$ denotes the real interest rate promised by
} 
a more realistic model would feature a nonnegativity constraint on the default rate. The appendix to this paper analyzes ways to implement this restriction.

Because in this economy the inflation rate is constant over time, the Euler equation (9) implies that the risk-free nominal interest rate is constant and given by $R_{t}^{f}=\pi^{*} \beta^{-1}$. But this is precisely the equilibrium value taken by the interest rate on government bonds. Therefore, the gross sovereign risk premium, given by the ratio of the rate of return on public debt to the risk-free rate, $R_{t} / R_{t}^{f}$, is constant and equal to unity.

\section{The Perils of Delaying Default: Unpleasant Default Arithmetics}

Thus far, we have considered only two alternative default policies. One is characterized by no default at any point in time and leads to (fiscalist) hyperinflation or hyperdeflation depending on initial conditions. The second default policy ensures a path for prices consistent with the government's inflation target and features a stochastic, unforecastable default rate.

But there are indeed infinitely many other possible default arrangements. Here we focus on one that captures certain aspects of observed pre-default dynamics. Namely, in practice, governments that follow unsustainable policies tend to procrastinate. Only when the economy is clearly embarked in an explosive path, such as a hyperinflation, do governments dare to make hard decisions, such as defaulting. An example is the pre-default transition in Argentina in the second half of 2001. A number of observers believed at the time that under the policy arrangement prevailing at the end of the De la Rua-Cavallo administration, described as a rigid peg to the dollar coupled with a precarious fiscal stance, default was simply a matter of time. ${ }^{7}$ At the end, this sentiments materialized and the Argentine government repudiated its outstanding financial obligations. First partially, via a debt swap in December of 2001, and shortly afterward, in January of 2002, totally. The painful economic depression and price stampid that followed the default led many to wonder whether the Argentine government had waited too long to default. When the policy mix is incompatible with long-run price stability, delaying default may prove counterproductive for two reasons. First, the longer the government waits to default, the higher is the inflation rate the economy is exposed to. Second, the longer the delay, the higher the default rate required to stabilize prices. This is the sense in which we introduce the concept of 'unpleasant default arithmetics.' To illustrate this point, consider a perfect-foresight environment and suppose

the government. The higher is this interest rate, the higher is the cost of serving the debt without defaulting.

${ }^{7}$ See, for example, the commentaries on Argentina published in The Economist on October 20-26, 2001, and The Washington Post, on October 22, 2001. 
that the government decides to delay default for $T>0$ periods. That is, the fiscal authority sets

$$
\delta_{t}=0 ; \quad 0 \leq t<T
$$

In period $T$, the government finally decides to default in a magnitude sufficient to ensure price stability. Formally, in periods $t \geq T$ the default rate is set in such a way that

$$
\pi_{t} \equiv \frac{P_{t}}{P_{t-1}}=\pi^{*} ; \quad t \geq T
$$

In this case, a rational expectations equilibrium is given by definition 1 and equations (15), (20), and (21). Because the default rate is zero before period $T$, the Euler equation (10) implies that

$$
R_{t}=\beta^{-1} \pi_{t+1} ; \quad t \leq T-2 .
$$

Combining this expression with the Taylor rule (15) we get $\pi_{t+1}=\pi^{*}+\alpha \beta\left(\pi_{t}-\pi^{*}\right)$ for $0 \leq t \leq T-2$, where we are assuming that $R^{*} \equiv \pi^{*} / \beta$. This expression implies the following pre-default time path for inflation

$$
\pi_{t}=\pi^{*}+(\alpha \beta)^{t}\left(\pi_{0}-\pi^{*}\right) ; \quad 0 \leq t \leq T-1
$$

In turn, assuming that $\tau_{t}=\tau$ for all $t$, where $\tau$ is a constant, equations (13) and (20) imply that the initial inflation rate is exogenously given by $\pi_{0}=R_{-1} B_{-1}(1-\beta) /\left(P_{-1} \tau\right)$. We are interested in the case

$$
\pi_{0}>\pi^{*}
$$

This assumption and equation (23) show that the longer the government waits to default, the higher the inflation rate the public must endure.

In period $T-1$, the Taylor rule (15) states that $\beta R_{T-1}=\pi^{*}+\alpha \beta\left(\pi_{T-1}-\pi^{*}\right)$. Combining this expression with equation (23) yields

$$
\beta R_{T-1}=\pi^{*}+(\alpha \beta)^{T}\left(\pi_{0}-\pi^{*}\right)
$$

Finally, in period $T$ the stabilization policy kicks in, so $\pi_{T}=\pi^{*}$. The Euler equation (10) evaluated at $t=T-1$ then implies that $\delta_{T}=1-\pi^{*} /\left(\beta R_{T-1}\right)$. Combining this expression 
with equation (24) yields the following solution for the default rate in period $T$ :

$$
\delta_{T}=1-\frac{\pi^{*}}{\pi^{*}+(\alpha \beta)^{T}\left(\pi_{0}-\pi^{*}\right)}
$$

This expression shows that the longer the government procrastinates the larger the rate of default necessary to bring about price stability. In the limit, as $T \rightarrow \infty$, the government is forced to default on the entire stock of public debt. Note that the government defaults only once, in period $T$. In periods $t \geq T$, the Taylor rule (15) implies that $R_{t}=\pi^{*} / \beta$, so that, by the Euler equation (10), $\delta_{t}=0$. Summarizing, we have that if the government delays default for $T$ periods, then

$$
\lim _{T \rightarrow \infty} \pi_{T-1}=\infty
$$

and

$$
\lim _{T \rightarrow \infty} \delta_{T}=1
$$

The intuition why a government that procrastinates for too long ends up defaulting on its entire obligations is simple. If the government puts off default for a sufficiently long period of time, the inflation rate in period $T-1$ climbs to a level far above its intended target $\pi^{*}$. As a result, the Taylor rule prescribes a very high nominal interest rate in that period. In period $T$, the inflation rate drops sharply to its target $\pi^{*}$. This means that the 'promised' (i.e., before default) real interest rate on government assets held between periods $T-1$ and $T$, given by $R_{T-1} / \pi^{*}$, experiences a drastic hike, generating a severe solvency problem, which the government resolves by defaulting.

Surprisingly, in this economy the stock of real public debt provides no indication of worsening fundamentals as the economy approaches the default crisis. In effect, the stock of public real debt, $b_{t} \equiv B_{t} / P_{t}$, remains constant along the entire transition. To see this, note that the government's budget constraint implies that $b_{0}=R_{-1} b_{-1} / \pi_{0}-\tau$. Using the fact that $\pi_{0}=R_{-1} B_{-1}(1-\beta) /\left(P_{-1} \tau\right)$, we obtain

$$
b_{0}=\beta \tau /(1-\beta) .
$$

At the same time, in periods $0<t \leq T-1$ we have that $b_{t}=R_{t-1} b_{t-1} / \pi_{t}-\tau=b_{t-1} / \beta-\tau$. (In the second equality we are using the fact that $\delta_{t}=0$ for $t<T$, so that the Euler equation (10) implies $R_{t}=\pi_{t+1} / \beta$.) Then, assuming that $b_{t-1}=\beta \tau /(1-\beta)$, we have that 
$b_{t}=\frac{\beta \tau}{1-\beta}$. It follows, by induction, that

$$
b_{t}=\frac{\beta \tau}{1-\beta} ; \quad 0 \leq t \leq T-1
$$

Note that the fact that the default rate is zero between periods 0 and $T-1$ implies that the interest-rate premium on public debt is zero between periods 0 and $T-2$. In period $T-1$ the premium jumps up to $\left(1-\delta_{T}\right)^{-1}-1$. Finally, in period $T$ the premium returns to zero and remains at that level forever. However, in a model were the date $T$ at which the government decides to 'pull the plug' is random, the interest rare premium will in general be positive for all $0<t<T$.

\section{$6 \quad$ Price Level Targeting}

We now turn our attention to another example of a monetary regime that, if not coupled with some sort of (intertemporal) balanced budget rule, can make default inevitable. Namely, price level pegs. ${ }^{8}$ By pegging the price level, the government gives up its ability to inflate away part of the real value of its liabilities in response to negative fiscal shocks. It is therefore clear that short of endogenous regular fiscal instruments able to offset such exogenous fiscal innovations, default emerges as a necessary outcome. As in the previous section, we are interested in consisting the equilibrium process of the default rate under these circumstances. It turns out that given the fiscal regime, the equilibrium default rate behaves quite differently under a price level peg than under a Taylor rule.

Formally, the monetary regime we wish to study in this section is given by:

$$
P_{t}=1 ; \quad t \geq 0
$$

The equilibrium conditions then include this rule and the equations contained in definition 1. Note that the constancy of the price level implies, by equation (9), that the risk-free interest rate is constant and equal to the inverse of the subjective rate of discount. That is,

$$
R_{t}^{f}=\beta^{-1}
$$

Using the facts that $P_{t}$ and $R_{t}^{f}$ are both constant at all times, we can rewrite the definition f equilibrium more compactly as:

\footnotetext{
${ }^{8}$ In open economies where PPP holds, governments interested in pegging the price level typically resort to pegging the exchange rate between the domestic currency and that of a low-inflation country. Recent examples include Argentina, Austria, and Hong-Kong.
} 
Definition 2 (Rational Expectations Equilibrium Under Price Level Targeting) $A$ rational expectations competitive equilibrium is a set of processes $\left\{B_{t}, R_{t}, \delta_{t}\right\}_{t=0}^{\infty}$ satisfying

$$
\begin{gathered}
1=\beta R_{t} E_{t}\left(1-\delta_{t+1}\right) \\
B_{t}=R_{t-1} B_{t-1}\left(1-\delta_{t}\right)-\tau_{t} \\
\lim _{j \rightarrow \infty} E_{t} \beta^{t+j+1} R_{t+j} B_{t+j}\left(1-\delta_{t+j+1}\right)=0 .
\end{gathered}
$$

and a fiscal-policy constraint further restricting the behavior of the default rate, given $R_{-1} B_{-1}$ and the exogenous process for lump-sum taxes $\left\{\tau_{t}\right\}_{t=0}^{\infty}$.

\subsection{The Equilibrium Stock of Public Debt}

Setting $P_{t}=1$ in equation (13), we obtain the following expression for the equilibrium default rate:

$$
\delta_{t}=1-\frac{\sum_{h=0}^{\infty} \beta^{h} E_{t} \tau_{t+h}}{R_{t-1} B_{t-1}}
$$

Note that because the price level is constant and normalized at one, the denominator on the right-hand side, $R_{t-1} B_{t-1}$, represents both nominal and real total government liabilities. It will prove convenient to write the above expression using the specific AR(1) process assumed for taxes. This yields

$$
\delta_{t}=1-\frac{(1-\beta)\left(\tau_{t}-\bar{\tau}\right)+(1-\beta \rho) \bar{\tau}}{R_{t-1} B_{t-1}(1-\beta)(1-\beta \rho)} .
$$

To obtain the equilibrium level of public debt, evaluate equation (27) at time $t+1$ and take expectations conditional on information available at time $t$. Then use equation (29) to eliminate $E_{t} \delta_{t+1}$ to get

$$
B_{t}=\sum_{h=1}^{\infty} \beta^{h} E_{t} \tau_{t+h} .
$$

According to this expression, the government's ability to absorb debt is dictated by the expected value of future tax receipts. Note that the level of debt is independent of the magnitude of liabilities assumed by the government in the past, $R_{t-1} B_{t-1}$. Under the assumed 
first-order autorregressive structure of taxes, the above expression becomes

$$
B_{t}=\frac{\beta \rho(1-\beta)\left(\tau_{t}-\bar{\tau}\right)+\beta(1-\beta \rho) \bar{\tau}}{(1-\beta)(1-\beta \rho)}
$$

By this formula, a given decline in current tax revenues obliges the government to engineer a larger cut in public debt the more persistent is the tax process.

\subsection{Impossibility of Pegging the Price Level Without Defaulting}

Evaluating equation (29), which describes the law of motion of the equilibrium default rate, at $t=0$, we obtain

$$
\delta_{0}=1-\frac{\sum_{h=0}^{\infty} \beta^{h} E_{0} \tau_{h}}{R_{-1} B_{-1}} .
$$

In period 0, the government cannot affect any of the variables entering the right-hand side of this expression. In effect, taxes are assumed to be exogenous, and initial total public liabilities are pre-determined. Consequently, the government has no control over the initial rate of default $\delta_{0}$. A negative initial tax shock leads inevitably to default. It follows that it is impossible to fix $\delta_{0}$ equal to zero.

A natural question is whether the government has the ability to arbitrarily fix the level of the default rate (at zero, say) in all periods following period 0 . The answer to this question is no. To see why, assume, contrary to our contention, that the government is capable of setting $\delta_{t}$ at a constant level $\bar{\delta}$ for all $t>0$. Then, evaluating (30) at $t+1$ we have that $R_{t}$ is implicitly given by

$$
\bar{\delta}=1-\frac{(1-\beta)\left(\tau_{t+1}-\bar{\tau}\right)+(1-\beta \rho) \bar{\tau}}{R_{t} B_{t}(1-\beta)(1-\beta \rho)}
$$

On the right-hand side, $\tau_{t+1}$ is measurable with respect to the information set available in period $t+1$ and $B_{t}$ is measurable with respect to information available in $t$. It follows that according to the above expression, $R_{t}$ is measurable with respect to information available in $t+1$, which is a contradiction, because, by assumption, the government announces $R_{t}$ in period $t$. It follows that the government cannot fix the rate of default for all $t>0$.

Although the government is unable to perfectly control the dynamics of the default rate, it can affect it on a limited basis. This is the focus of what follows. 


\subsection{Default Rule 1}

Consider, for example, a policy rule whereby in each period $t>0$ the government does not default unless the tax-to-debt ratio falls below a certain threshold. Specifically, suppose that the government restricts $\delta_{t}$ in the following way:

$$
\text { Default Rule 1: } \quad \delta_{t}\left\{\begin{array}{ll}
<0 & \text { if } \tau_{t} / B_{t-1}>\alpha \\
=0 & \text { if } \tau_{t} / B_{t-1}=\alpha \\
>0 & \text { if } \tau_{t} / B_{t-1}<\alpha
\end{array} \quad t=1,2, \cdots\right.
$$

where the threshold $\alpha$ is chosen arbitrarily by the fiscal authority. In this case, a rational expectations equilibrium is given by this expression and definition 2. According to the above rule, the government defaults on part of the public debt when the tax-to-debt ratio $\tau / B_{t-1}$ is below the announced threshold $\alpha$. This situation takes place in periods of relatively low tax realizations. On the other hand, when the tax-to-debt ratio exceeds the threshold $\alpha$, the government chooses to reward bond holders by implementing a subsidy proportional to the size of their portfolios.

The default rule (33) can be implemented by an appropriate choice of the interest rate promised on public debt, $R_{t}$. To see this, consider any period $t>0$ in which $\tau_{t}=\alpha B_{t-1}$. In such periods, the equilibrium condition (28) becomes

$$
B_{t}=R_{t-1} B_{t-1}-\alpha B_{t-1}
$$

Using equation (32) to eliminate $B_{t}$ we obtain

$$
\frac{\beta \rho(1-\beta)\left(\alpha B_{t-1}-\bar{\tau}\right)+\beta(1-\beta \rho) \bar{\tau}}{(1-\beta)(1-\beta \rho)}=R_{t-1} B_{t-1}-\alpha B_{t-1}
$$

Solving this expression for the interest rate, yields

$$
R_{t}=\alpha+\frac{\beta \rho(1-\beta)\left(\alpha B_{t}-\bar{\tau}\right)+\beta(1-\beta \rho) \bar{\tau}}{B_{t}(1-\beta)(1-\beta \rho)} ; \quad t=0,1, \ldots
$$

This expression and equation (32), which expresses $B_{t}$ as a function of $\tau_{t}$ only, jointly describe the equilibrium law of motion of the interest rate as a function of current taxes. Combining the above expression with equation (30) to eliminate $R_{t}$, we find that the equilibrium default rate in periods $t>0$ is given by

$$
\delta_{t}=1-\frac{(1-\beta)\left(\tau_{t}-\bar{\tau}\right)+(1-\beta \rho) \bar{\tau}}{\alpha(1-\beta)(1-\beta \rho) B_{t-1}+\beta \rho(1-\beta)\left(\alpha B_{t-1}-\bar{\tau}\right)+\beta(1-\beta \rho) \bar{\tau}} .
$$


Figure 1: Equilibrium Dynamics Under Default Rule 1
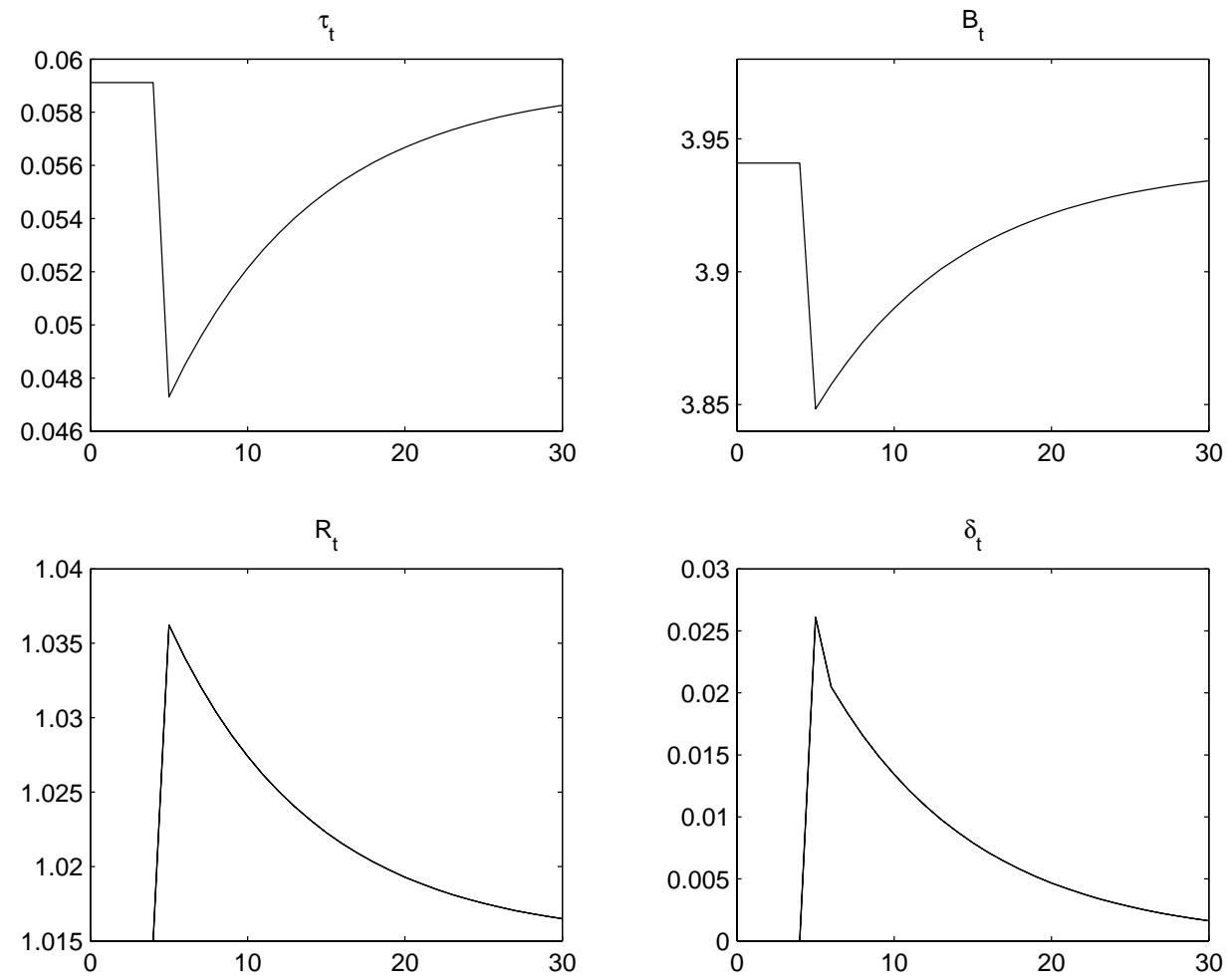

Figure 1 illustrates how the model economy operates under default rule 1 . It depicts the equilibrium dynamics of taxes, public debt, the interest rate, and the default rate in response to a negative tax innovation. The model is parameterized as follows. The time period is meant to be one quarter. The subjective discount factor $\beta$ is set equal to $1 /(1+.06 / 4)$, which implies an annual real (and nominal) interest rate of 6 percent. Quarterly output, $y$, is normalized at unity. The initial level of government liabilities, $R_{-1} B_{-1}$, is set at 4 , implying a debt-to-annual-GDP ratio of one. The average tax rate, $\bar{\tau}$ is set at $(1-\beta) R_{-1} B_{-1}$, so that if the tax rate in period zero equals its unconditional expectation $\bar{\tau}$, then the equilibrium default rate in that period is zero. The serial correlation of taxes, $\rho$, is assumed to be 0.9 . Finally, we set the threshold $\alpha$ equal to $(1-\beta) / \beta$. This value implies that the government chooses to default whenever the tax-to-debt ratio is below its long-run level $(1-\beta) / \beta$.

The initial situation depicted in the figure is one in which taxes are equal to their long-run level $\bar{\tau}$. In period 5 , the economy experiences a negative tax surprise. Specifically, in that period taxes fall 20 percent below average; that is, $\epsilon_{5}=-0.2 \bar{\tau}$, or $\tau_{5}=0.8 \bar{\tau}$. Tax innovations after period 5 are nil (i.e., $\epsilon_{t}=0$ for $t>5$ ). Note that the fact that the realizations of the tax innovation are zero in periods other than period five $\left(\left(\epsilon_{t}=0\right.\right.$ for $\left.t \neq 5\right)$ does not mean that the economy operates under certainty for $t \neq 5$. This is because in any period $t \geq 0$ agents are uncertain about future realizations of $\epsilon$. Between periods 0 and 4 , the tax-to-debt 
ratio is at its long-run level. As a result, the government honors its obligations in full $\left(\delta_{t}=0\right.$ for $t \leq 4)$. In period 5 , in response to the 20 percent decline in tax revenue, the government defaults on about 2.5 percent of the public debt. Because the tax-to-debt ratio remains below its long-run level along the entire transition, the government continues to default after period 5. The cumulative default, given by $\sum_{t=5}^{\infty} \delta_{t}$, is about 23 percent. Before period 5 , the interest rate on public debt equals the risk-free rate of 1.5 percent reflecting no default expectations $\left(E_{t} \delta_{t+1}=0\right)$. In period 5 , the interest rate on government bonds jumps to 3.6 percent and then returns monotonically to its steady-state level of 1.5 percent. The fact that the risk-free interest rate is constant (Eq. (26)) implies that the sovereign risk premium, $R_{t} / R_{t}^{f}$, is proportional to $R_{t}$. Thus, a deterioration in fiscal conditions triggers a persistent increase in sovereign risk.

\subsection{Default Rule 2}

As a second example, consider a default rule whereby the government defaults only if the tax rate is below a certain fraction of output. Formally,

$$
\text { Default Rule 2: } \quad \delta_{t}\left\{\begin{array}{ll}
<0 & \text { if } \tau_{t}>\alpha y \\
=0 & \text { if } \tau_{t}=\alpha y \\
>0 & \text { if } \tau_{t}<\alpha y
\end{array} \quad t=1,2, \cdots\right.
$$

where $\alpha$ is a parameter chosen by the government, and $y$ is the constant endowment. The full set of equilibrium conditions is then given by the above rule and the equations listed in definition 2. It is easy to show that under this rule the interest rate on public debt is given by,

$$
R_{t}=\frac{\alpha}{B_{t}}+\frac{\beta \rho(1-\beta)(\alpha y-\bar{\tau})+\beta(1-\beta \rho) \bar{\tau}}{B_{t}(1-\beta)(1-\beta \rho)} ; \quad t=0,1, \ldots
$$

Figure 2 displays the model's dynamics under default rule 2. The parameterization of the model is identical to that used under rule 1, except for $\alpha$, which is now set equal to $\bar{\tau} / y$ so as to induce pre-shock dynamics identical to those depicted in figure 1. The experiment shown in figure 2 is the same as the one implemented under rule 1 . Namely, the tax innovation $\epsilon_{t}$ is 0 for all $t \neq 5$ and is equal to $-0.20 \bar{\tau}$ in period 5 , so that in that period tax revenues fall by 20 percent. For comparison, figure 1 reproduces with broken lines the dynamics under rule 1. The dynamics under both rules are qualitatively identical. The interest rate and the default rate rise in period 5 and then converge monotonically to their respective steady states. However, the convergence is somewhat faster under default rule 1 . To see why this 
Figure 2: Equilibrium Dynamics Under Default Rule 2
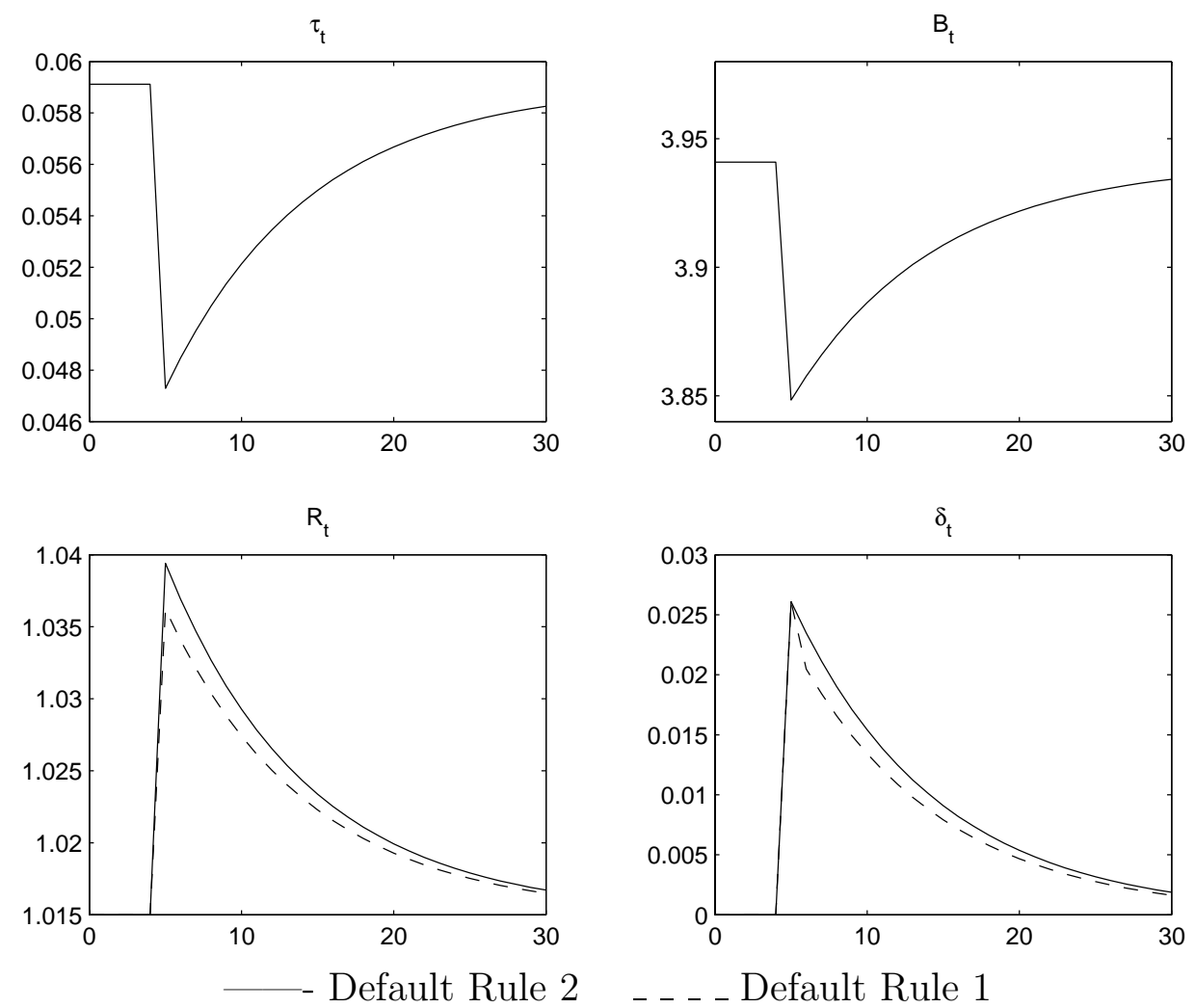
is the case, note that in periods $t>5$ the tax-to-output ratio $\tau_{t} / y$ is relatively further below its steady state level than the tax-to-debt ratio, $\tau_{t} / B_{t-1}$. This is because the stock of public debt adjusts down in response to the tax cut, whereas output remains constant.

\subsection{Default Rule 3: An Interest Rate Peg}

As a final example, consider the case of a peg of the rate of return on public debt. Specifically, assume that the government sets the interest rate on public debt equal to the risk-free interest rate. That is,

$$
R_{t}=R_{t}^{f}=\beta^{-1}
$$

According to this policy, the government completely eliminates the sovereign risk premium. In this case the equilibrium is given by definition 2 and the above rule.

Contrary to what happens under rules 1 and 2, under the interest rate peg considered here the equilibrium default rate is an iid random variable with mean zero. That is, the default rate is completely unforecastable. To see this, combine the interest-rate rule (35) with the Euler equation (27) to get

$$
E_{t} \delta_{t+1}=0
$$

Figure 3 depicts the model's dynamics under the assumed interest rate peg. For comparison, the figure also reproduces the dynamics implied by default rule 1 . Under the interest rate peg, the default rate jumps up in period 5, when the tax shock takes place, but immediately returns to zero. Note that because the magnitude of the jump in the default rate in period 5 is about the same under both rules and because the default rate is serially uncorrelated under rule 3 but persistent under rule 1, the cumulative default is much higher under rule 1. How can this be possible if the initial level of public debt as well as the path of taxes are the same in both economies? The reason is that under rule 3 the interest rate is lower than under rule 1, which makes the post-shock debt burden including interest also smaller under rule 3 .

\section{Conclusion}

A number of emerging economies have or are facing the need to default. These countries display heterogeneous policy arrangements. A central aim of this paper is to characterize the precise way in which monetary policy affects the equilibrium behavior of default and sovereign 
Figure 3: Equilibrium Dynamics Under Default Rule 3
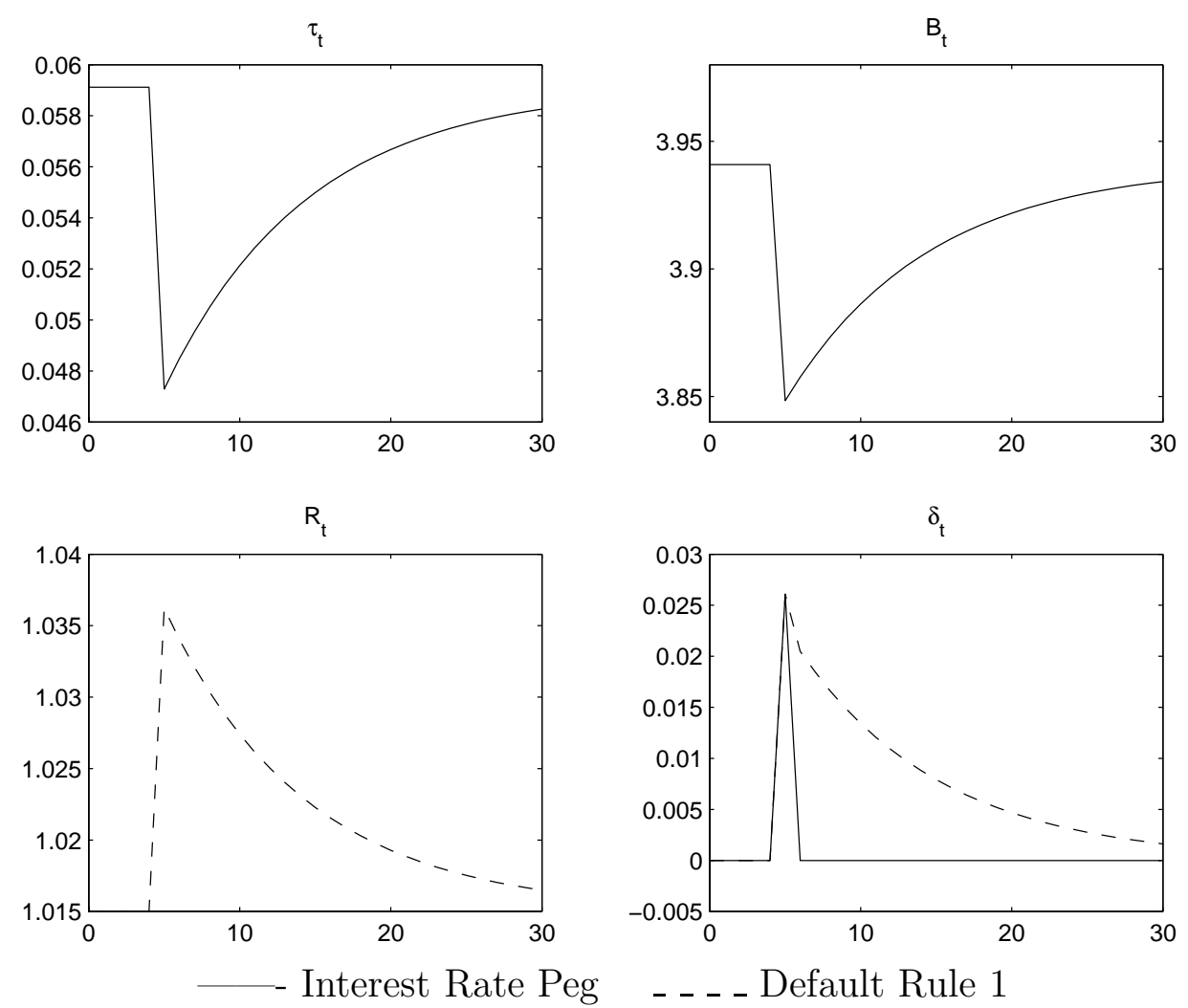
risk premia. We find that monetary policy indeed plays a significant role in shaping the equilibrium distribution of default and risk premia. For example, in the economy analyzed in section 4, where the government follows a Taylor-type interest rate feedback rule, price stability requires that the government defaults only by surprise. As a result, the country risk premium is nil at all times even though the fiscal authority reneges of its obligations from time to time. On the other hand, in an economy where the central bank pegs the price level, like the one studied in section 6 , both default and the country risk premium can be highly persistent. But the precise fiscal and monetary regime in place are not the only characteristics of policy behavior that contribute to giving form to the dynamics of default. An equally important role is played by the government's attitude toward making tough decisions. Some governments have a natural tendency to put off as much as possible unavoidable painful measures. This paper shows that in the case of default, procrastination can have unintended consequences. For instance, in the economy where the monetary authority follows a Taylor rule, postponing default leads not only to an explosive inflation path, but also to an eventual default that is larger than the one that would have taken place if the government had not tried to gain time. It is in this sense that we speak of an unpleasant arithmetics in attempting to substitute inflation for default. 


\section{Appendix}

\section{Taylor Rules and Non-Negative Default Rates}

Consider an economy whose equilibrium conditions are given by the equations listed in definition 1 and equations (15) and (17). Suppose in addition, that the default rate is constrained to be nonnegative, that is

$$
\delta_{t} \geq 0 ; \quad \forall t
$$

- Clearly, equations (18) and (19) that in periods when the expected present discounted value of (regular) taxes exceeds the real value of government liabilities, the government must transfer resources to the public. Since the government cannot implement this transfers via negative values of $\delta$, it must materialize them through regular transfers. We refer to this type of transfers as extraordinary. Specifically, suppose that the government has the ability to transfer in a lump-sum fashion the difference between the expected present discounted value of primary surpluses and current real liabilities. Let total taxes, $\tau_{t}$, be given by the sum of ordinary taxes, $\tau_{t}^{o}$, and extraordinary (negative) taxes, $\tau_{t}^{e}$,

$$
\tau_{t}=\tau_{t}^{o}+\tau_{t}^{e}
$$

Ordinary taxes follow an exogenous $\mathrm{AR}(1)$ process of the form

$$
\tau_{t}^{o}-\bar{\tau}^{o}=\rho\left(\tau_{t-1}^{o}-\bar{\tau}^{o}\right)+\epsilon_{t},
$$

We conjecture that the government can implement the equilibrium defined above with nonnegative default rates by following the following rule for extraordinary taxes:

$$
\tau_{0}^{e}=\min \left(0, g_{0}\left(\tau_{0}^{o}, R_{-1} B_{-1} / P_{-1}\right)\right)
$$

and

$$
\tau_{t}^{e}=\min \left(0, g\left(\tau_{t-1}^{o}, \epsilon_{t}\right)\right), \quad t>0
$$

where the functions $g_{0}$ and $g$ are to be determined. Under our conjecture, the Taylor rule (15) implies that the interest rate is constant and given by

$$
R_{t}=R^{*}
$$


where $R^{*}>0$ is the exogenously determined interest rate target. It follows from the above expression for $\tau_{t}^{e}$ that

$$
\begin{aligned}
E_{t} \tau_{t+1}^{e} & =\int_{\left\{\epsilon: g\left(\tau_{t}^{o}, \epsilon\right) \leq 0\right\}} g\left(\tau_{t}^{o}, \epsilon\right) f(\epsilon) d \epsilon \\
& \equiv H_{1}\left(\tau_{t}^{o}, g\right)
\end{aligned}
$$

where $f$ is the density function of the standard normal distribution. Also,

$$
\begin{aligned}
E_{t} \tau_{t+2}^{e} & =E_{t} E_{t+1} \tau_{t+2}^{e} \\
& =E_{t} H_{1}\left(\tau_{t+1}^{o}, g\right) \\
& =\int_{-\infty}^{\infty} H_{1}\left(\bar{\tau}^{o}+\rho\left(\tau_{t}^{o}-\bar{\tau}^{o}\right)+\epsilon, g\right) f(\epsilon) d \epsilon \\
& \equiv H_{2}\left(\tau_{t}^{o}, g\right)
\end{aligned}
$$

In general, we can write

$$
E_{t} \tau_{t+j}^{e}=H_{j}\left(\tau_{t}^{o}, g\right) ; \quad j \geq 1
$$

We include the second argument in the functions $H_{j}, j \geq 1$, to emphasize their dependence upon the unknown function $g$. Clearly, equations (18) and

$$
\delta_{t}=1-\frac{\pi^{*}}{\beta R^{*}} \frac{\sum_{h=0}^{\infty} \beta^{h} E_{t} \tau_{t+h}}{\sum_{h=0}^{\infty} \beta^{h} E_{t-1} \tau_{t+h}} ; \quad t \geq 1
$$

(this last expression introduced in footnote 6) continue to be valid here because their derivation does not depend upon the assumed tax structure. Given the AR(1) process specified for ordinary taxes, we can write $E_{t} \sum_{h=0}^{\infty} \beta^{h} \tau_{t+h}^{o}=\gamma_{1} \tau_{t-1}^{o}+\gamma_{2} \epsilon_{t}+\gamma_{3}$ and $E_{t-1} \sum_{h=0}^{\infty} \beta^{h} \tau_{t+h}^{o}=$ $\gamma_{4} \tau_{t-1}^{o}+\gamma_{5}$, where $\gamma_{i}, i=1,2,3,4,5$ are known parameters. Then, using this expressions and equation (36), we have that for $t>0$ the default rate is given by:

$$
\delta_{t}=1-\frac{\pi^{*}}{\beta R^{*}} \frac{\tau_{t}^{e}+\sum_{h=1}^{\infty} \beta^{h} H_{h}\left(\tau_{t}^{o}, g\right)+\gamma_{1} \tau_{t-1}^{o}+\gamma_{2} \epsilon_{t}+\gamma_{3}}{\sum_{h=0}^{\infty} \beta^{h} H_{h+1}\left(\tau_{t-1}^{o}, g\right)+\gamma_{4} \tau_{t-1}^{o}+\gamma_{5}} ; \quad t \geq 1
$$

Setting $\delta_{t}=0$ and $\tau_{t}^{e}=g\left(\tau_{t-1}^{o}, \epsilon\right)$ we obtain the following implicit functional equation in $g$

$$
0=1-\frac{\pi^{*}}{\beta R^{*}} \frac{g\left(\tau_{t-1}^{o}, \epsilon_{t}\right)+\sum_{h=1}^{\infty} \beta^{h} H_{h}\left(\tau_{t}^{o}, g\right)+\gamma_{1} \tau_{t-1}^{o}+\gamma_{2} \epsilon_{t}+\gamma_{3}}{\sum_{h=0}^{\infty} \beta^{h} H_{h+1}\left(\tau_{t-1}^{o}, g\right)+\gamma_{4} \tau_{t-1}^{o}+\gamma_{5}} ; \quad t \geq 1
$$


Similarly, using (18) and having found the function $g$, the function $g^{0}$ solves

$$
0=1-\pi^{*} \frac{g^{0}\left(\tau_{0}^{o}, R_{-1} B_{-1} / p_{-1}\right)+\sum_{h=1}^{\infty} \beta^{h} H_{h}\left(\tau_{0}^{o}, g\right)+\gamma_{6} \tau_{0}^{o}+\gamma_{7}}{R_{-1} B_{-1} / P_{-1}},
$$

where $\gamma_{6} \tau_{0}^{o}+\gamma_{7}=E_{0} \sum_{h=0}^{\infty} \beta^{h} \tau_{h}^{9}$ and $\gamma_{6}$ and $\gamma_{7}$ are known parameters. 


\section{References}

Benhabib, Jess, Stephanie Schmitt-Grohé, and Martín Uribe, "The Perils of Taylor Rules," Journal of Economic Theory, 96, January-February 2001(a), 40-69.

Benhabib, Jess, Stephanie Schmitt-Grohé, and Martín Uribe, "Avoiding Liquidity Traps," Journal of Political Economy, 110, June 2002, 535-563.

Clarida, Richard, Jordi Galí, and Mark Gertler, "Monetary Policy Rules in Practice: Some International Evidence," European Economic Review 42, 1998, 1033-1067.

Cochrane, John H., "A Frictionless View of U.S. Inflation," National Bureau of Economic Research Macroeconomics Annual, 13, 1998, 323-384.

Eaton, Jonathan and Raquel Fernández, "Sovereign Debt," in Gene Grossman and Kenneth Rogoff editors, Handbook of International Economics, Volume 3, North Holland, 1995, chapter 39, p. 2031-2077.

Krugman, P.R., "A Model of Balance of Payments Crises," Journal of Money, Credit and Banking, 11, August 1979, 311-325

Leeper, Eric, "Equilibria Under 'Active' and 'Passive' Monetary and Fiscal Policies," Journal of Monetary Economics, 27, 1991, 129-147.

Loyo, Eduardo, "Tight Money Paradox on the Loose: A Fiscalist Hyperinflation," manuscript, Harvard University, 1999.

Schmitt-Grohé, Stephanie and Martín Uribe, "Price Level Determinacy and Monetary Policy Under a Balanced-Budget Requirement," Journal of Monetary Economics 45, February 2000, 211-246.

Sims, C., "A Simple Model for the Study of the Determination of the Price Level and the Interaction of Monetary and Fiscal Policy," Economic Theory, 4, 1994, 381-399.

Taylor, John B., "Discretion Versus Policy Rules in Practice," Carnegie-Rochester Series on Public Policy, 39, 1993, 195-214.

Woodford, M., "Monetary Policy and Price Level Determinacy in a Cash-in-Advance Economy," Economic Theory, 4, 1994, 345-380. 